
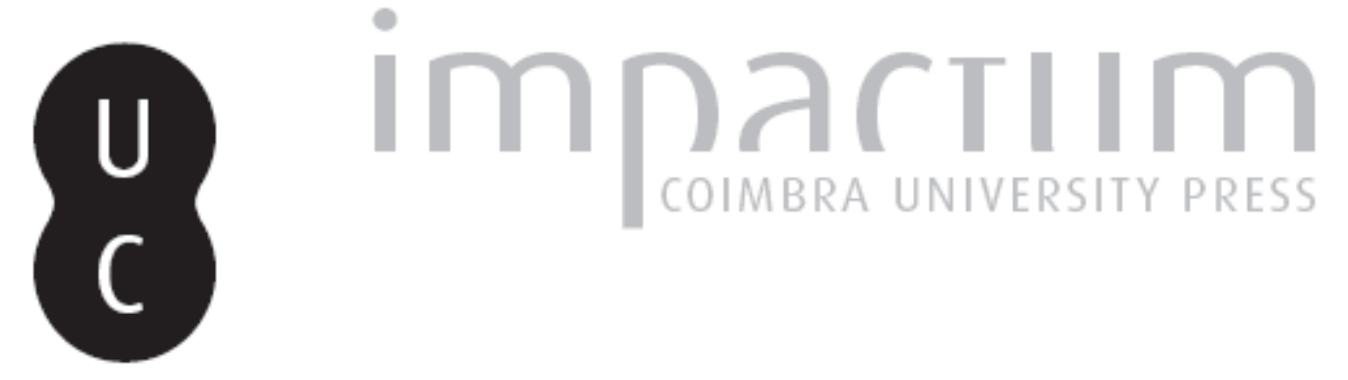

Estudo populacional de 6 STRs (TH01, TPOX, CSF1PO, D7S820, D13S317 e D16S539) na regiâo Centro de Portugal
Autor(es):
Manco, Licínio; Arede, Pedro; Silva, Isabel; Alvarez, Manuela; Abade, Augusto

Publicado por: CIAS - Centro de Investigação em Antropologia e Saúde

URL

persistente:

URI:http://hdl.handle.net/10316.2/28878

DOI:

DOI:http://dx.doi.org/10.14195/2182-7982_25_8

Accessed : $\quad$ 26-Apr-2023 12:29:41

A navegação consulta e descarregamento dos títulos inseridos nas Bibliotecas Digitais UC Digitalis, UC Pombalina e UC Impactum, pressupõem a aceitação plena e sem reservas dos Termos e Condições de Uso destas Bibliotecas Digitais, disponíveis em https://digitalis.uc.pt/pt-pt/termos.

Conforme exposto nos referidos Termos e Condições de Uso, o descarregamento de títulos de acesso restrito requer uma licença válida de autorização devendo o utilizador aceder ao(s) documento(s) a partir de um endereço de IP da instituição detentora da supramencionada licença.

Ao utilizador é apenas permitido o descarregamento para uso pessoal, pelo que o emprego do(s) título(s) descarregado(s) para outro fim, designadamente comercial, carece de autorização do respetivo autor ou editor da obra.

Na medida em que todas as obras da UC Digitalis se encontram protegidas pelo Código do Direito de Autor e Direitos Conexos e demais legislação aplicável, toda a cópia, parcial ou total, deste documento, nos casos em que é legalmente admitida, deverá conter ou fazer-se acompanhar por este aviso. 


\section{Antropologia Portuguesa}

Volume $24-25 \cdot 2007-2008$

Departamento de Antropologia | Universidade de Coimbra

\section{Dossier Temático \\ CLAUDE LÉVI-STRAUSS}




\title{
Estudo populacional de 6 STRs (TH01, TPOX, CSF1PO, D7S820, D13S317 e D16S539) na região Centro de Portugal
}

\author{
Licínio Manco, Pedro Arede, Isabel Silva, Manuela Alvarez, Augusto Abade \\ Departamento de Antropologia \\ Faculdade de Ciências e Tecnologia \\ Universidade de Coimbra \\ Imanco@antrop.uc.pt
}

Resumo As frequências alélicas de 6 STRs autossómicos (TH01, TPOX, CSF1PO, D7S820, D13S317 e D16S539), correntemente utilizados em estudos forenses, foram estimadas numa amostra de indivíduos não aparentados naturais da região Centro de Portugal (N=70-104). Não se verificaram desvios significativos ao equilíbrio de Hardy-Weinberg para os marcadores estudados. Os resultados foram comparados com os obtidos em estudos realizados noutras regiões do país (Norte, Centro e Sul de Portugal, Madeira e Açores) e em diversas populações Europeias não tendo sido encontradas diferenças estatisticamente significativas para a maioria dos loci, o que mostra, por um lado, semelhança genética da região Centro de Portugal com estas populações e, por outro, a consistência dos resultados encontrados.

Palavras-chave Genética populacional; polimorfismos de DNA; STRs; Região Centro de Portugal.

\begin{abstract}
Allele frequencies for six autossomal STRs (TH01, TPOX, CSF1PO, D7S820, D13S317 and D16S539), currently used for genetic identity testing, were determined in a sample of healthy unrelated individuals from Central Portugal $(\mathrm{N}=70-104)$. All systems showed conformity with Hardy-Weinberg expectations. Comparison of allele frequencies between Central Portugal and population samples from other Portuguese regions (North, Center and South of Portugal, Madeira and Azores) and several European populations showed no significant differences for most loci which reveal genetic similarity as also robustness on results.
\end{abstract}

Key words Population genetics; DNA polymorphisms; STRs; Central Portugal.

\section{Introdução}

Microssatélites ou Short Tandem Repeats (STRs) são sequências repetitivas de DNA com unidades que variam de 2 a 6 pares de bases, 
muito abundantes e aleatoriamente distribuídas no genoma humano. Os microssatélites são altamente polimórficos e, como tal, largamente utilizados como marcadores em áreas tão importantes como o mapeamento genético, a genética de populações e a investigação forense, sendo disponibilizados em kits comerciais multiplex destinados a testes de paternidade e à identificação individual. Em genética populacional, a informação facultada pelo estudo de STRs tem vindo a permitir elucidar muitos aspectos do processo evolutivo humano (Jorde et al., 1997) e a definir a estrutura genética das populações humanas (Rosenberg et al., 2002).

Diversos estudos de genética populacional utilizando microssatélites têm vindo a ser realizados em amostras da população Portuguesa, nomeadamente na região Norte de Portugal (Alves et al., 2001; Amorim et al., 2001; Pinheiro et al., 2005), Madeira (Fernandes et al., 2002) e Açores (Velosa et al., 2002). Todavia, na região Centro e Sul do país os estudos disponíveis utilizando STRs autossómicos são escassos (Fernandes e Brehm, 2002). No sentido de contribuir para minorar esta falta, foram utilizados 6 STRs (TH01, TPOX, CSF1PO, D13S317, D7S820 e D16S539), correntemente incluídos em kits comerciais destinados a estudos forenses, com o objectivo principal de estimar frequências alélicas numa amostra populacional da região Centro de Portugal. Os resultados foram comparados com os obtidos em estudos realizados noutras regiões do país e em diversas populações Europeias.

\section{Material e Métodos}

Foi estudada uma amostra populacional $(\mathrm{N}=70-104)$ de indivíduos não aparentados naturais da região Centro de Portugal (distritos localizados entre os rios Douro e Tejo). Todas as amostras foram colhidas após consentimento informado.

O DNA genómico foi extraído a partir de sangue total pelo método Chelex (Walsh et al., 1991). As regiões do genoma que incluem os marcadores em estudo foram amplificadas por PCR multiplex utilizando os primers descritos para os kits GenePrint STR Multiplex System (Promega) (loci TH01, TPOX e CSF1PO) e GenePrint ${ }^{\circledR}$ SilverSTR ${ }^{\circledR}$ III System (Promega) (loci D7S820, D13S317 e D16S539), marcados com Cy5. Os produtos da amplificação foram submetidos a electroforese em gel de poliacrilamida $8 \%$ no sequenciador automático ALFexpress II (Amersham Pharmacia Biotech). 
O tamanho dos fragmentos foi determinado automaticamente utilizando o programa ALFwin Fragment Analyser 1.00.

Parâmetros estatísticos que incluíram valores de frequências alélicas e de heterozigotia observada e esperada, bem como o valor exacto de $P$ (nível de significância $=0,05$ ) para avaliar o equilíbrio de Hardy-Weinberg (Guo e Thompson, 1992) e a diferenciação entre populações (Raymond e Rousset, 1995), foram calculados recorrendo ao software Arlequin, vs 3.01 (Excoffier et al., 2005; http://cmpg.unibe.ch/software/arlequin3/).

\section{Resultados e Discussão}

Os valores das frequências alélicas obtidos na região Centro de Portugal, bem como os valores de heterozigotia esperada e observada, encontram-se discriminados na Tabela 1. Não se verificaram desvios significativos ao equilíbrio de Hardy-Weinberg para os marcadores em estudo.

Tabela 1. Frequências alélicas e outros parâmetros estatísticos estimados na amostra populacional da região Centro de Portugal para os 6 marcadores polimórficos autossómicos estudados.

\begin{tabular}{|c|c|c|c|c|c|c|}
\hline Alelos & $\begin{array}{c}\text { TH01 } \\
(\mathbf{N}=104)\end{array}$ & $\begin{array}{l}\text { TPOX } \\
(\mathrm{N}=97)\end{array}$ & $\begin{array}{c}\text { CSF1PO } \\
(\mathrm{N}=91)\end{array}$ & $\begin{array}{c}\text { D7S820 } \\
(\mathrm{N}=70)\end{array}$ & $\begin{array}{c}\text { D13S317 } \\
(\mathrm{N}=72)\end{array}$ & $\begin{array}{c}\text { D16S539 } \\
(N=74)\end{array}$ \\
\hline 6 & 0,163 & 0,005 & & & & \\
\hline 7 & 0,173 & & & 0,029 & & \\
\hline 8 & 0,130 & 0,552 & 0,005 & 0,179 & 0,132 & 0,027 \\
\hline 9 & 0,231 & 0,046 & 0,017 & 0,164 & 0,069 & 0,115 \\
\hline 9.3 & 0,293 & & & & & \\
\hline 10 & 0,010 & 0,072 & 0,352 & 0,271 & 0,049 & 0,081 \\
\hline 11 & & 0,294 & 0,253 & 0,207 & 0,361 & 0,338 \\
\hline 12 & & 0,031 & 0,302 & 0,136 & 0,243 & 0,203 \\
\hline 13 & & & 0,066 & 0,014 & 0,111 & 0,216 \\
\hline 14 & & & 0,005 & & 0,035 & 0,020 \\
\hline$p$ & 0,083 & 0,066 & 0,119 & 0,244 & 0,200 & 0,573 \\
\hline Ho & 0,779 & 0,567 & 0,637 & 0,786 & 0,778 & 0,784 \\
\hline He & 0,791 & 0,611 & 0,720 & 0,813 & 0,778 & 0,782 \\
\hline
\end{tabular}

N: $\mathrm{n}^{\circ}$ de indivíduos; $\boldsymbol{p}$ : equilíbrio de Hardy-Weinberg, teste exacto; Ho: heterozigotia observada; He: heterozigotia esperada. 
O perfil genético (distribuição de alelos, valores de frequências alélicas e valores de heterozigotia) obtido para a amostra da região Centro de Portugal é semelhante ao obtido noutros estudos populacionais em diferentes regiões do país. Os valores de heterozigotia (He) variam entre $61,1 \%$, para o locus TPOX, e 81,3\%, para o marcador D7S820, valores semelhantes aos obtidos em diferentes regiões do continente português (Gusmão et al., 2000; Alves et al., 2001; Fernandes e Brehm, 2002; Pinheiro et al., 2005).

O teste exacto de diferenciação com base nas frequências alélicas revelou não haver diferenças estatisticamente significativas entre as frequências alélicas obtidas na região Centro de Portugal e noutras amostras da população Portuguesa, nomeadamente da região Norte (Alves et al., 2001; Amorim et al., 2001; Fernandes e Brehm, 2002; Pinheiro et al., 2005), Centro (Fernandes e Brehm, 2002), Sul (Fernandes e Brehm, 2002), Madeira (Fernandes et al., 2002) e Açores (Velosa et al., 2002), com excepção do marcador TPOX relativamente à amostra populacional da Madeira e a uma amostra populacional da região Norte (Fernandes e Brehm, 2002) $(P<0,05)$ (Tabela 2). As frequências alélicas obtidas para os 6 loci foram também comparadas com as de outras populações Europeias, nomeadamente de Espanha - País Basco (Pérez-Miranda et al., 2005) e Andaluzia (PérezMiranda e Herrera, 2005), Grécia (Kovatsi et al., 2005), Polónia (Czarny et al., 2005) e Itália (Garofano et al., 1998), tendo sido obtidas diferenças estatisticamente significativas para diversos marcadores $(P<0,05)$. Todavia, após aplicação da correcção de Bonferroni (SISA), o nível de significância baixou para 0,0083 e foram apenas observados valores significativos para os loci: TPOX, na comparação com a população da Madeira $(P=0,001 \pm 0,001)$; D16S539, na comparação com as populações do País Basco - província de Navarra $(P=0,0000 \pm 0,0000)$, da Andaluzia $(P=0,0036 \pm 0,001)$ e da Polónia $(P=0,0001 \pm 0,0001)$; D13S317, na comparação com País Basco - província de Guipúzcoa $(P=0,0049 \pm 0,0032)$, e CSF1PO, na comparação com Andaluzia $(P=0,000 \pm 0,000)$ (Tabela 2). 


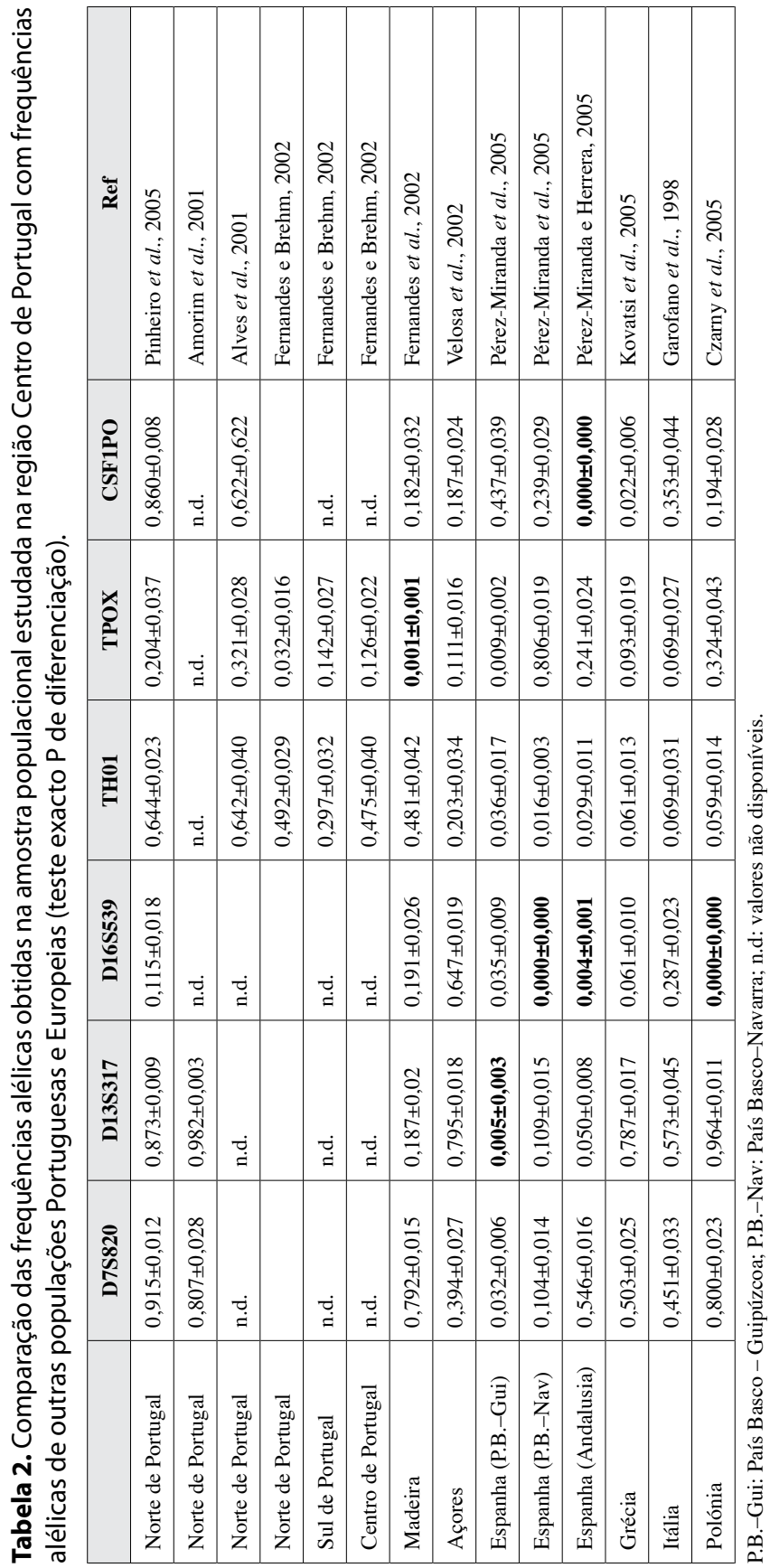




\section{Conclusão}

Neste trabalho foi apresentado um estudo de diversidade genética na região Centro de Portugal com base em 6 marcadores autossómicos do tipo STR correntemente utilizados em estudos forenses. As frequências alélicas de 4 destes loci (CSF1PO, D7S820, D13S317 e D16S539) são aqui reportadas pela primeira vez numa amostra populacional da região Centro de Portugal, contribuindo assim para atenuar a falta de dados populacionais disponíveis na literatura respeitantes a esta região do país. Os resultados foram comparados com os obtidos noutros estudos realizados em Portugal e noutras populações Europeias não tendo sido encontradas diferenças estatisticamente significativas para a maioria dos loci, o que mostra, por um lado, semelhança genética da região Centro de Portugal com essas populações e, por outro, consistência nos resultados obtidos.

\section{Agradecimentos}

Este trabalho foi financiado em parte pelo Centro de Investigação em Antropologia e Saúde (CIAS) - Faculdade de Ciências e Tecnologia da Universidade de Coimbra. Agradecemos ao Departamento de Hematologia do Centro Hospitalar de Coimbra, EPE, as facilidades concedidas na utilização do sequenciador ALFexpress.

\section{Bibliografia}

Alves, C.; Gusmão, L.; Pereira, L.; Amorim, A. 2001. STR data (CD4, CSF1PO, F13A01, FES/FPS, MBPB, TH01, TPOX) from North Portugal. Forensic Science International, 123: 76-77.

Amorim, A.; Gusmão, L.; Alves, C. 2001. STR data (AmpFlSTR Profiler Plus) from North Portugal. Forensic Science International, 115: 119-121.

Czarny, J.; Grzybowski, T.; Derenko, M. V.; Malyarchuk, B. A.; Sliwka, D. M. 2005. Genetic variation of 15 STR loci (D3S1358, vWA, FGA, TH01, TPOX, CSF1PO, D5S818, D13S317, D7S820, D16S539, D2S1338, D8S1179, D21S11, D18S51, and D19S433) in populations of north and central Poland. Forensic Science International, 147: 97-100. 
Excoffier, L.; Laval, G.; Schneider, S. 2005. Arlequin ver. 3.01: an integrated software package for population genetics data analysis. Evolutionary Bioinformatics Online, 1: 47-50.

Fernandes, A. T.; Brehm, A. F. 2002. Population data of five STRs in three regions from Portugal. Forensic Science International, 129: 72-74.

Fernandes, A.T.; Brehm, A.; Alves, C.; Gusmão, L.; Amorim, A. 2002. Genetic profile of the Madeira Archipelago population using the new PowerPlex 16 System Kit. Forensic Science International, 125: 281-283.

Garofano, L.; Pizzamiglio, M.; Vecchio, C.; Lago, G.; Floris, T.; D’Errico, G.; Brembilla, G.; Romano, A.; Budowle, B. 1998. Italian population data on thirteen short tandem repeat loci: HUMTH01, D21S11, D18S51, HUMVWFA31, HUMFIBRA, D8S1179, HUMTPOX, HUMCSF1PO, D16S539, D7S820, D13S317, D5S818, D3S1358. Forensic Science International, 12: 53-60.

Guo, S. W.; Thompson, E. A. 1992. Performing the exact test of Hardy-Weinberg proportions for multiple alleles. Biometrics, 48: 361-372.

Gusmão, L.; Sánchez-Diz, P.; Alves, C.; Lareu, M. V.; Carracedo, A.; Amorim, A. 2000. Genetic diversity of nine STRs in two northwest Iberian populations: Galicia and northern Portugal. International Journal of Legal Medicine, 114: 109-113.

Jorde, L. B.; Rogers, A. R.; Bamshad, M.; Watkins, W. S.; Krakowiak, P.; Sung, S.; Kere, J.; Harpending, H. C. 1997. Microsatellite diversity and the demographic history of modern humans. Proceedings of the National Academy of Sciences of the United States of America, 94: 3100-3103.

Kovatsi, L.; Parsons, T. J.; Just, R. S.; Irwin, J. A. 2005. Genetic variation for 15 autosomal STR loci (PowerPlex 16) in a population sample from northern Greece. Forensic Science International, 159: 61-63.

Pérez-Miranda, A. M.; Herrera, R. J. 2005. Genetic data on 13 STR loci in the Andalusian (South Spain) population. Legal Medicine, 7: 201-203.

Pérez-Miranda, A. M.; Alfonso-Sánchez, M. A.; Kalantar, A.; García-Obregón, S.; de Pancorbo, M. M.; Peña, J. A.; Herrera, R. J. 2005. Microsatellite data support subpopulation structuring among Basques. Journal of Human Genetics, 50: 403-414.

Pinheiro, M. F.; Cainé, L.; Pontes, L.; Abrantes, D.; Lima, G.; Pereira, M. J.; Rezende, P. 2005. Allele frequencies of sixteen STRs in the population of Northern Portugal. Forensic Science International, 148: 221-223.

Raymond, M.; Rousset, F. 1995. An exact test for population differentiation. Evolution, 49: 1280-1283. 
Rosenberg, N. A.; Pritchard, J. K.; Weber, J. L.; Cann, H. M.; Kidd, K. K.; Zhivotovsky, L. A.; Feldman, M. W. 2002. Genetic structure of human populations. Science, 298: 2381-2385.

Velosa, R. G.; Fernandes, A. T.; Brehm, A. 2002. Genetic profile of the Açores Archipelago population using the new PowerPlex 16 System Kit. Forensic Science International, 129: 68-71.

Walsh, P. S.; Metzger, D. A.; Higuchi, R. 1991. CHELEX1 100 as a medium for simple extraction of DNA for PCR-based typing from forensic material. BioTechniques, 10: 506-513.

Artigo recebido a 28 de Março de 2008 e aceite a 21 de Julho de 2008. 